\title{
Characterization of phytohormone and transcriptome profiles during protocorm- like bodies development of Paphiopedilum
}

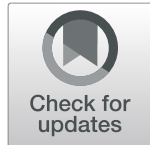

Beiyi Guo ${ }^{1,2}$, Songjun Zeng ${ }^{1,3^{*}} \mathbb{D}$, Yuying Yin ${ }^{1,2}$, Lin $\mathrm{Li}^{1}$, Guohua Ma ${ }^{1}$, Kunlin $\mathrm{Wu}^{1}$ and Lin Fang ${ }^{1,4^{*}}$

\begin{abstract}
Background: Paphiopedilum, commonly known as slipper orchid, is an important genus of orchid family with prominent horticultural value. Compared with conventional methods such as tillers and in vitro shoots multiplication, induction and regeneration of protocorm-like bodies (PLBs) is an effective micropropagation method in Paphiopedilum. The PLB initiation efficiency varies among species, hybrids and varieties, which leads to only a few Paphiopedilum species can be large-scale propagated through PLBs. So far, little is known about the mechanisms behind the initiation and maintenance of PLB in Paphiopedilum.

Results: A protocol to induce PLB development from seed-derived protocorms of Paphiopedilum SCBG Huihuang90 ( $P$. SCBG Prince $\times$ P. SCBG Miracle) was established. The morphological characterization of four key PLB developmental stages showed that significant polarity and cell size gradients were observed within each PLB. The endogenous hormone level was evaluated. The increase in the levels of indoleacetic acid (IAA) and jasmonic acid (JA) accompanying the PLBs differentiation, suggesting auxin and JA levels were correlated with PLB development. Gibberellic acid (GA) decreased to a very low level, indicated that GA inactivation may be necessary for shoot apical meristem (SAM) development.

Comparative transcriptomic profiles of four different developmental stages of $P$. SCBG Huihuang 90 PLBs explore key genes involved in PLB development. The numbers of differentially expressed genes (DEGs) in three pairwise comparisons (A vs B, B vs C, C vs D) were 1455, 349, and 3529, respectively. KEGG enrichment analysis revealed that DEGs were implicated in secondary metabolite metabolism and photosynthesis. DEGs related to hormone metabolism and signaling, somatic embryogenesis, shoot development and photosynthesis were discussed in detail.

Conclusion: This study is the first report on PLB development in Paphiopedilum using transcriptome sequencing, which provides useful information to understand the mechanisms of PLB development.
\end{abstract}

Keywords: Paphiopedilum, Transcriptome analysis, Protocorm-like bodies, Somatic embryo, Organogenesis

\footnotetext{
* Correspondence: zengsongjun@scib.ac.cn; linfang@scbg.ac.cn

'Key Laboratory of South China Agricultural Plant Molecular Analysis and Gene Improvement, South China Botanical Garden, Chinese Academy of Sciences, Guangzhou 510650, China

Full list of author information is available at the end of the article
}

C C The Author(s). 2021 Open Access This article is licensed under a Creative Commons Attribution 4.0 International License, which permits use, sharing, adaptation, distribution and reproduction in any medium or format, as long as you give appropriate credit to the original author(s) and the source, provide a link to the Creative Commons licence, and indicate if changes were made. The images or other third party material in this article are included in the article's Creative Commons licence, unless indicated otherwise in a credit line to the material. If material is not included in the article's Creative Commons licence and your intended use is not permitted by statutory regulation or exceeds the permitted use, you will need to obtain permission directly from the copyright holder. To view a copy of this licence, visit http://creativecommons.org/licenses/by/4.0/ The Creative Commons Public Domain Dedication waiver (http://creativecommons.org/publicdomain/zero/1.0/) applies to the data made available in this article, unless otherwise stated in a credit line to the data. 


\section{Background}

Paphiopedilum Pfitzer (Orchidaceae) is commonly known as slipper orchid due to the resemblance of its pouch-shaped lip to a lady's slipper. Paphiopedilum is one of the most primordial genera of Orchidaceae, comprising 107 species found so far [1]. Certain species of Paphiopedilum have high ornamental value because their flowers are available in unique patterns. Paphiopedilum spp. are important horticultural plants and an endangered species. Wild populations of Paphiopedilum $s p p$. are critically endangered due to habitat destruction and unsustainable harvest. All wild species of Paphiopedilum are listed in the Convention on International Trade in Endangered Species of Wild Fauna and Flora (CITES) Appendix I, and their trade is prohibited [2].

Conventional Paphiopedilum orchid propagation through axillary buds division from the mother plant is unproductive and time-consuming. Currently, the general method of rapid propagation of Paphiopedilum is asymbiotic seed germination. However, the efficiency of asymbiotic germination is limited by the flowering period and capsule maturity $[3,4]$. Fully mature Paphiopedilum seeds are usually difficult to germinate $[3,5]$. In vitro propagation of Paphiopedilum showed that when the mature plant organ of shoots, leaves, or roots were used as explants, the induction of adventitious buds is difficult, and the propagation efficiency is low $[6,7]$.

Orchids have a unique reproductive system. The seeds are minute and simple, lacking a well-defined endosperm and cotyledon. A small spherical tuber-like structure formed from germinating seeds is defined as a protocorm. PLBs, whose general structure and growth characteristics are similar to those of protocorm, are derived from somatic cells $[8,9]$. PLBs are the ideal explants for in vitro propagation because PLBs have the ability to generate secondary PLBs and differentiate into complete plants. Under suitable stimulation, PLBs can form a meristematic zone characterized by small cells and no intercellular spaces (some studies refer to it as SAM). Shoots will differentiate from this meristematic zone [10]. In this process, in addition to the changes in endogenous hormones, many storage products undergo metabolism or transport $[9,11]$.

In Paphiopedilum, it is hard to induce PLBs, which leads to the failure of the popularization of this propagation system. Although in vitro propagation system through PLBs formation of several Paphiopedilum orchids, such as $P$. hangianum [12], $P$. rothschildianum [13], and $P$. nivrum [14], had been established, such attempts on many other Paphiopedilum orchids failed. PLBs induction ability varies greatly among different orchid species and varieties. PLBs of $P$. SCBG Huihuang90 can be induced and proliferate continuously, so it is an excellent plant material for the study on PLBs initiation and development.
Traditionally, researchers have considered both protocorms and PLBs as the "somatic embryo" of orchids because of the morphological and compositional similarities $[9,15]$. However, a comparative transcriptome analysis proposed that PLBs and protocorms are molecularly distinct from zygotic embryos in Phalaenopsis aphrodite. Instead, PLB regeneration may be derived from the shoot regeneration process [16]. In general, the molecular mechanisms of PLB regulation remain unclear. Besides, whether PLBs are indeed somatic embryos is also controversial. Many marker genes of somatic embryo or genes involved in the regulation of somatic embryogenesis have been identified, such as SOMATIC EMBRYOGENESIS LIKE RECEPTOR KINASE (SERK), BABYBOOM (BBM), WUSCHEL (WUS), and CLAVATA (CLV) [17-19]. SERK has been proven to play an important role in somatic embryogenesis [18]. WUS and $C L V$ generally maintain stem cell and cell differentiation in stem meristem [19]. WUSCHEL RELATED HOMEO$B O X(W O X)$ genes are homologous genes of WUS. WOXs regulate early embryo patterning $[20,21]$ and contribute to maintaining the stem cell meristem [22, 23]. $B B M$ is an important transcription factor involved in plant embryogenesis and a key regulator of plant cell totipotency, [24]. BBM can induce the formation of differentiated somatic cells and somatic embryos by activating signal transduction pathways. Analysis of the expression patterns of these genes is worthwhile to investigate the nature of PLBs.

The role of plant hormones during in vitro propagation has been extensively studied. Many studies suggested auxin was a prerequisite for callus induction from protocorm and subsequent PLB maintenance [25]. Studies indicated that auxin influenced protocorm development. In many orchid species, such as Spathoglottis plicata [26, 27], Oncidium [28], and Cymbidium mastersii [29], exogenous auxin application increased protocorm numbers or influenced protocorm morphology during germination. Previous studies showed that exogenous auxin application promoted an undifferentiated state, but reduction or removal of auxin from the culture media resulted in shoot formation [25]. Other plant hormones such as GA and JA also play a significant role in PLB development [30, 31]. Although numerous studies have proven that plant growth regulators (PGRs) play a significant role in PLB induction and development [8], few studies have been conducted on the changes of endogenous hormone content during Paphiopedilum PLB induction and development. Endogenous auxin is synthesized in protocorm and affects the growth and development of protocorm and PLBs. IAA is the most common naturally endogenous auxin [32]. The content of IAA is affected by the synthesis, degradation, and transport of IAA, and it functions through signal 
transduction pathways. TRYPTOPHAN AMIDOTRANSFERASE OF ARABIDOPSIS (TAA1) and TAARelated (TAR1) family proteins synthesize IPyA from tryptophan, while YUCCA family proteins catalyze the conversion of IPyA to IAA [33, 34]. DIOXYGENASE OF AUXIN OXIDATION (DAO), which belongs to the 2oxoglutarate (2OG) $\mathrm{Fe}(\mathrm{B})$ oxygenase family, is a key enzyme in the IAA oxidation pathway [35]. Main function of DAO is to catalyze the oxidation of IAA to 2oxoindole-3-acetic acid (oxIAA) in plants [36]. Free IAA can be polar transported to the site of action by auxin transport carrier and participate in signal regulation. Plant-specific PIN-formed (PIN) proteins directly promote cellular auxin efflux [37-39]. Members of the influx carriers AUXIN RESISTANT1/ LIKE AUXIN RESISTANT (AUX1/LAX) are functional auxin influx carriers and mediate auxin-related developmental events in different organs and tissues [40, 41].

Although plant tissue culture has been widely used to propagate orchids, large-scale propagation for Paphiopedilum by tissue culture is still a challenge. In this study, PLBs were successfully induced from seed-derived protocorms of $P$. SCBG Huihuang90. The morphological characteristics and level of major endogenous hormones of PLB at different developmental stages were assessed to further understand the biological process of PLBs initiation and development. Comparative transcriptome analysis during $P$. SCBG Huihuang90 PLB initiation and development provided valuable insights into the gene regulatory programs that characterize the PLB developmental process.

\section{Results}

Morphological characterization of PLB development

The growth process of PLBs was divided into four stages based on their morphological characteristics. 2,4dichlorophenoxyacetic acid (2,4-D) was used to induce protocorms which were derived from germinating of $\mathrm{P}$. SCBG Huihuang90 seeds to form the mass of callus-like meristem (Fig. 1a). The mass of meristem (stage A) was the original material of the PLB induction. At this stage, the inside of the explant was green and part of the edge was light yellow. The surface of the explant was uneven (Fig. 1a). After that, PLBs formed and gradually covered the surface of the mass of meristem (Fig. 1b). It meant that the mass of meristem differentiated into the PLBs mass (stage B). The PLBs mass and the meristem mass were easily distinguished because the PLBs mass had distinct spherical protuberances densely distributed on the outer surface, while the meristem mass appeared lumplike with no fixed shape. The single spherical protrusion was a single PLB, which could eventually develop into a complete plantlet. Next, parts of the PLBs mass differentiated into plantlets (stage C; Fig. 1c). The materials at stage $\mathrm{C}$ contained a mixture of shoots and PLBs. Finally, the PLBs mass differentiated into plantlets with green leaves (stage D; Fig. 1d).

The microstructure change of PLBs at stages A, B, C, and $\mathrm{D}$ were further characterized at the cellular level through histological observations. The meristem mass was mainly composed of aggregates of large cells without intercellular spaces and had compact smaller cell clusters inside (Fig. 2a). These compact small cells might
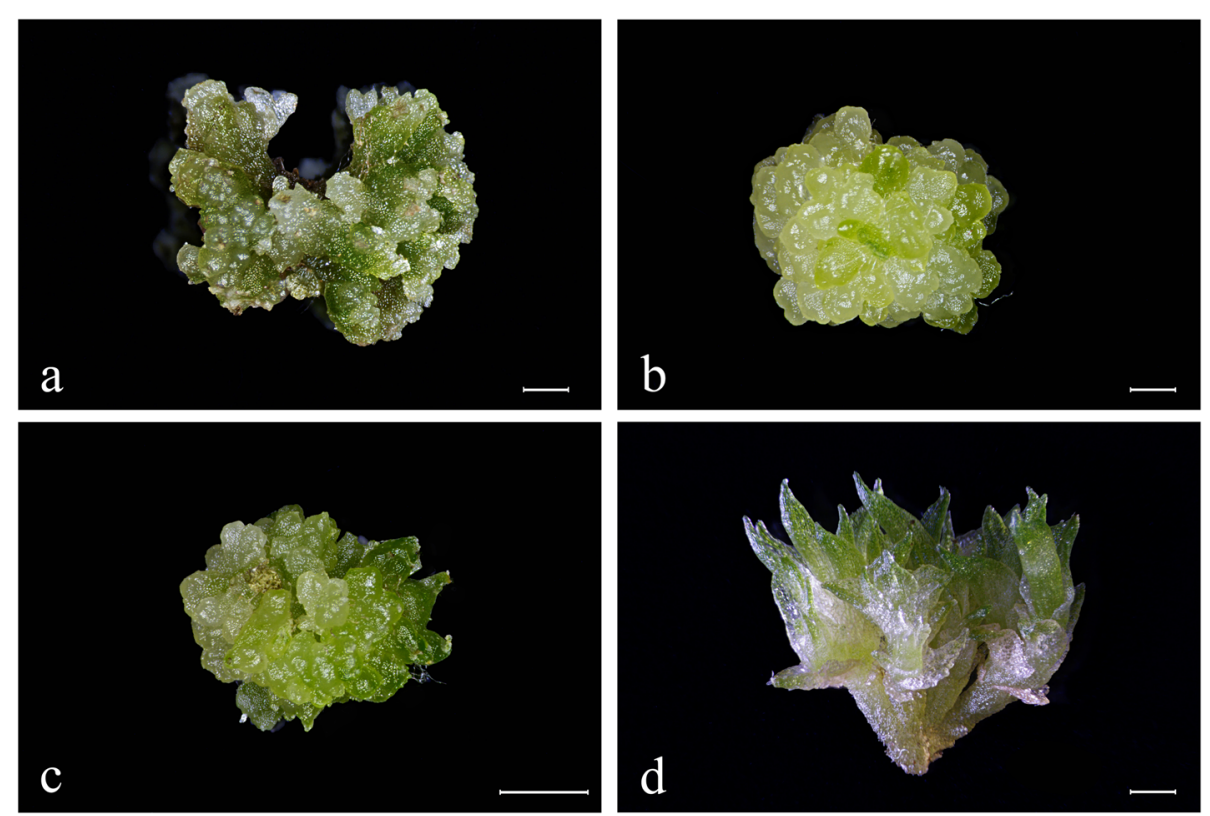

Fig. 1 Morphological characterization of the PLBs at four different stages used for RNA-seq analysis. a Stage A: Meristem mass. b Stage B: newly emerged PLBs. c Stage C: Mixture of PLBs and shoots. d Stage D: Cluster shoots (Scale bar =1000 $\mu \mathrm{m}$ ) 


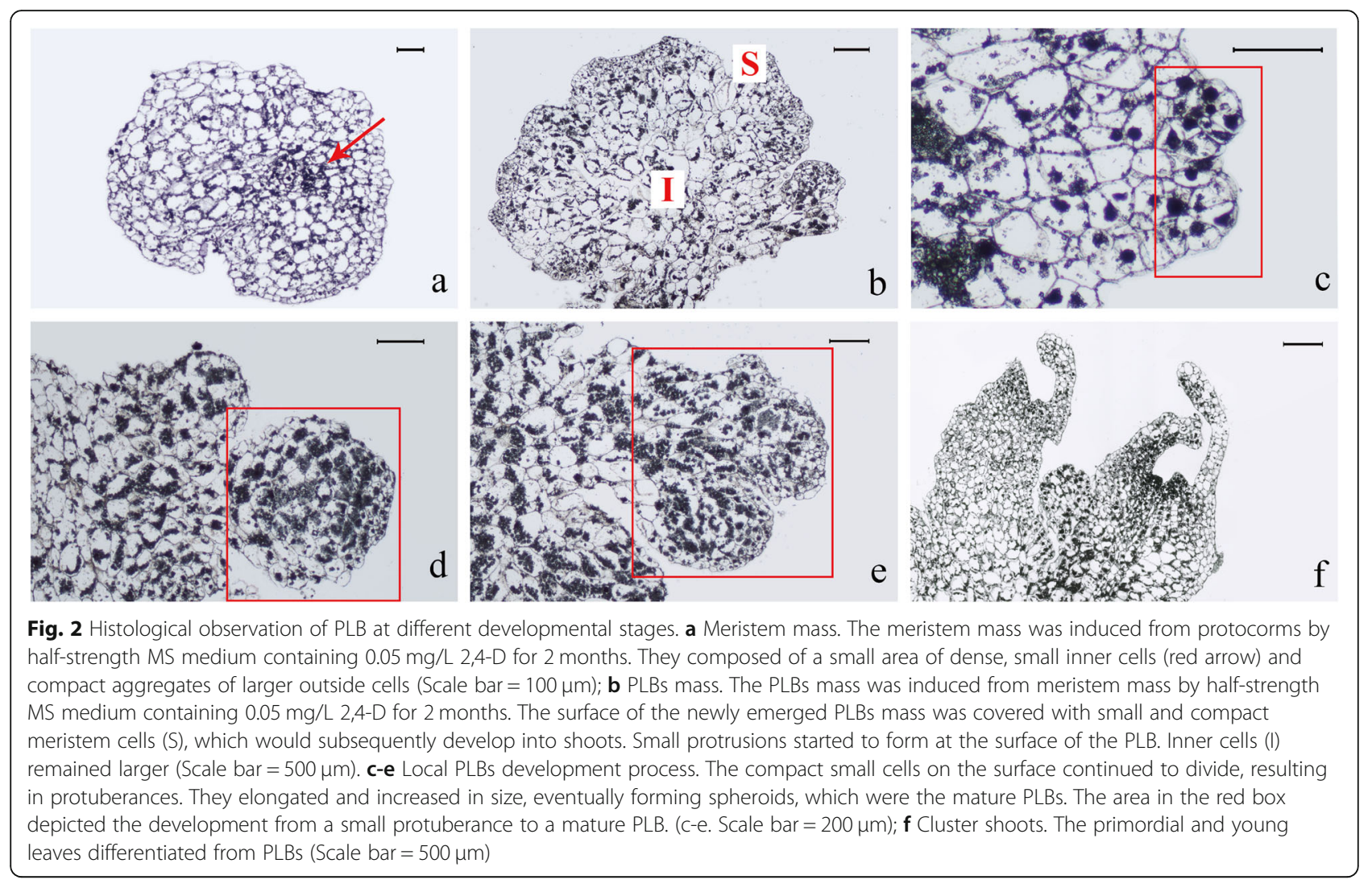

be the center of vigorous division and contribute to the continuous proliferation of the meristem mass by active cell division [13]. As the meristem mass began to differentiate into the PLBs mass, several layers of smaller cells covered on its surface and became tightly packed, while the basal cells remained larger (Fig. 2b). Small protrusions started to form at the surface of newly emerged PLBs mass. Further division of the compact meristem cells, resulting in the elongation and size increase of the protuberances. They eventually formed spheroids, which were the mature PLBs (Fig. 2c, d, e) and shown distinct growth polarity and cell size gradients. The cells at the base of PLB had a different cell fate from those at the apex. The PLB remained polar and continued to elongate (Fig. 2e) until they differentiated into the shoots (Fig. 2f). The primordial and young leaves differentiated from apical cells of PLBs, transforming PLBs into plantlets.

\section{Change of endogenous hormones during PLB initiation and development}

The coordinated interaction of endogenous hormones such as IAA, JA, ABA, trans-zeatin (TZR), and GAs plays multiple important roles in callus and SAM development. The content of several endogenous hormones was determined along with the PLB developmental process.
The content of IAA was significantly lower at stage A and stage $\mathrm{B}$ than that at stage $\mathrm{C}$ and stage $\mathrm{D}$. The IAA content was $1.38 \mathrm{ng} \mathrm{g}^{-1}$ fresh weight at stage $\mathrm{B}$. The content of IAA at stage $\mathrm{C}$ became 1.8 times higher than that at stage A (Fig. 3a). The content of IAA increased with PLBs differentiation until they completely differentiated into shoots. These results suggested that the change in IAA levels may be correlated with PLB development and shoot formation.

The content of $\mathrm{GA}_{3}$ decreased to a low level of around $0.06 \mathrm{ng} \mathrm{g}^{-1}$ fresh weight from stage A to stage B (Fig. 3d). This was consistent with previous reports showing that $\mathrm{GA}_{3}$ inactivation was required for the activity of the SAM [42-44]. JA content increased sharply during PLBs differentiation into shoots. At stage D, the content of JA was $61.445 \mathrm{ng} \mathrm{g}^{-1}$ fresh weight and significantly higher than other growth stages (Fig. 3b). Previous studies showed that the presence of JA in the medium stimulated the PLB and shoot formation in Hybrid Cymbidium [45]. The level of ABA and TZR stayed relatively constant throughout the whole PLB developmental process (Fig. 3c, e).

\section{De novo assembly and functional annotation}

In total, the RNA-seq of $12 \mathrm{cDNA}$ libraries of explants from four different developmental stages (stage A, B, C, and $\mathrm{D}$ ) produced approximately $80.78 \mathrm{~Gb}$ clean reads after removing adapters and filtering low-quality reads 


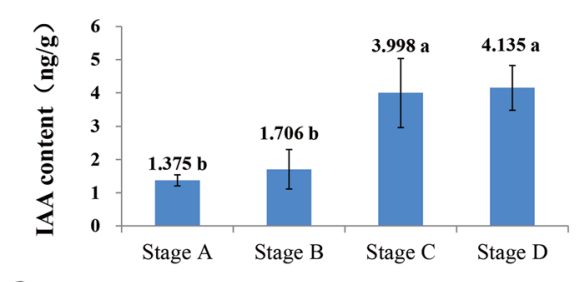

$\mathbf{a}$
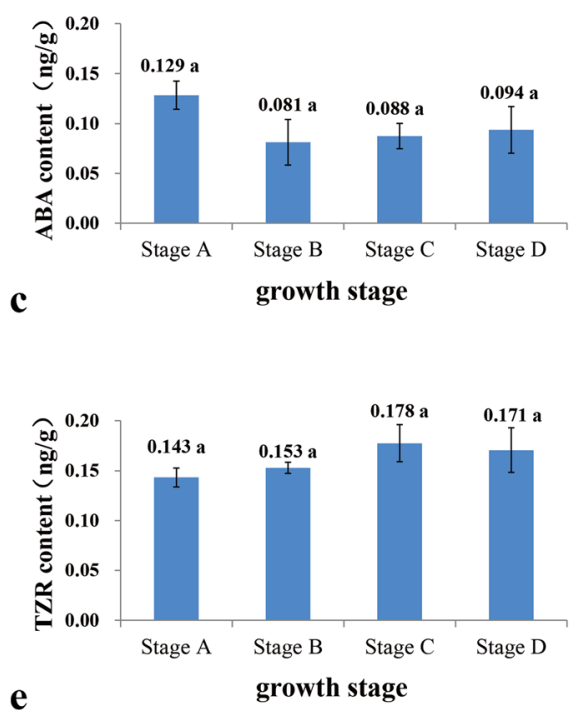

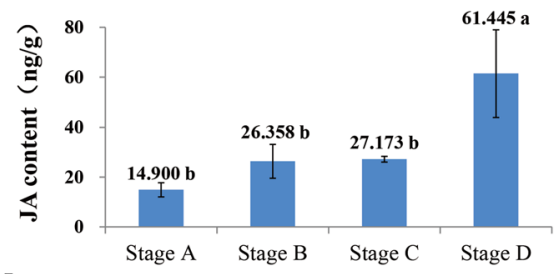

b

growth stage

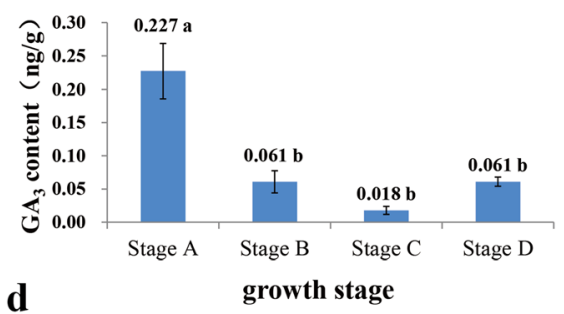

d

Fig. 3 Endogenous IAA (a), JA (b), ABA (c), GA (d), and TZR (e) contents at four different developmental stages of PLBs measured by HPLC. Data represent the average of three biological replicates. Values represent means \pm SE $(n=3)$. Bars with different letters are significantly different according to Duncan's multiple range test at a $P$ value $<0.05$. Stage A served as control

and over $10 \%$ of unknown nucleotides from raw data. The detailed statistics of clean reads are shown in Table 1. Overall, for all clean reads, the Q30 was over $92.35 \%$ and the GC content ranged from 47.53 to 48.80 . High-quality sequencing data was de novo assembled and generated 615,869 transcripts with N50 length of

Table 1 Detailed statistics of clean reads

\begin{tabular}{lllll}
\hline Samples & Read Number & Base Number & GC Content & $\% \geq \mathbf{Q 3 0}$ \\
\hline Stage A-01 & $18,310,566$ & $5,493,169,800$ & 47.53 & 92.52 \\
Stage A-02 & $21,732,828$ & $6,519,848,400$ & 47.73 & 92.35 \\
Stage A-03 & $26,813,456$ & $8,044,036,800$ & 48.01 & 92.89 \\
Stage B-01 & $23,605,550$ & $7,081,665,000$ & 48.11 & 93.54 \\
Stage B-02 & $20,321,782$ & $6,096,534,600$ & 48.12 & 93.24 \\
Stage B-03 & $19,516,643$ & $5,854,992,900$ & 47.96 & 93.71 \\
Stage C-01 & $20,398,668$ & $6,119,600,400$ & 47.72 & 93.29 \\
Stage C-02 & $23,179,966$ & $6,953,989,800$ & 47.94 & 93.81 \\
Stage C-03 & $20,303,802$ & $6,091,140,600$ & 48.14 & 93.14 \\
Stage D-01 & $22,296,877$ & $6,689,063,100$ & 48.56 & 93.01 \\
Stage D-02 & $24,393,463$ & $7,318,038,900$ & 48.62 & 93.19 \\
Stage D-03 & $28,401,917$ & $8,520,575,100$ & 48.8 & 93.01 \\
\hline
\end{tabular}

$1131 \mathrm{bp}$. A total of 223,079 longest transcripts were selected as unigenes, with mean length and N50 length of 757.33 and 923, respectively. The detailed results of de novo assembly are shown in Supplemental Table S1.

To determine the functional annotations, software BLAST (http://blast.ncbi.nlm.nih.gov/Blast.cgi) was used to compare the information of sequence or amino acid sequence of unigenes to 7 databases: NR, Swiss-Prot, Kyoto Encyclopedia of Genes and Genomes (KEGG), Clusters of Orthologous Groups (COG), euKaryotic Orthologous Groups (KOG), Gene Ontology (GO), and Protein family (Pfam). Table 2 shows that the total number of annotated unigenes was 105,795. Among them, 19,383 (8.69\%), 56,553 (25.35\%), 13,733 (6.16\%), 58,590 (26.26\%), 30,782 (13.8\%), 51,766 (23.21\%), and 104,149 (46.69\%) unigenes were annotated by COG, GO, KEGG, KOG, Pfam, Swiss-Prot, and NR database, respectively.

\section{Differential gene expression analysis and KEGG enrichment}

To understand the mechanism of PLB regeneration at the molecular level, the DEGs between samples were analyzed. To detect DEGs, | log2(Fold Change) $\mid \geq 1$ and 
Table 2 Annotated unigenes statistics of different databases

\begin{tabular}{lll}
\hline Annotated databases & Number of annotated unigene & Percentage (\%) \\
\hline COG & 19,383 & 8.69 \\
GO & 56,553 & 25.35 \\
KEGG & 13,733 & 6.16 \\
KOG & 58,590 & 26.26 \\
Pfam & 30,782 & 13.80 \\
Swiss-Prot & 51,766 & 23.21 \\
NR & 104,149 & 46.69 \\
All & 105,795 & 47.42 \\
\hline
\end{tabular}

false discovery rate $(\mathrm{FDR})<0.05$ were used as screening criteria. The total number of DEGs was 5331 (Fig. 4). In order to understand the differential genes between different periods for analysis, three comparison groups between successive growth stages were designed: stage A vs stage $B(A$ vs $B)$, stage $B$ vs stage $C$ ( $B$ vs $C$ ), stage $C$ vs stage $\mathrm{D}(\mathrm{C}$ vs $\mathrm{D})$. The comparison group $C$ vs $\mathrm{D}$ contained the largest number of DEGs, with 3527 DEGs, of which 1994 were upregulated and 1533 were downregulated (Fig. 4b). In the comparison group A vs B group, the number of DEGs was 1455, with 966 upregulated and 489 downregulated (Fig. 4b). The comparison group $B$ vs $C$ contained the least number of DEGs, with only 349 , of which 205 were upregulated and 144 were downregulated (Fig. 4b). In the three comparison groups, the number of upregulated genes was greater than the number of downregulated genes. There were 70 differential genes shared by the three comparison groups, and there were 1078, 74, and 3221 unique DEGs in group A vs B, $B$ vs $C$, and $C$ vs $D$, respectively (Fig. 4a). These specifically expressed genes might regulate distinctive physiological processes during the formation and development of P. SCBG Huihuang90 PLBs. A total of 4293 (80.53\%) genes were annotated according to at least one database
(Table 3). Among the seven databases, in all comparison groups, NR database annotated the most genes (73.7581.55\%), followed by Swiss-Prot (54.85-62.78\%).

KEGG enrichment analysis of DEGs in the comparison group $\mathrm{A}$ vs $\mathrm{B}$ and $\mathrm{B}$ vs $\mathrm{C}$ showed that the biosynthesis of secondary metabolites (ko01110) pathway contained the greatest number of DEGs, with 74 and 16, respectively. In the early stage of PLB development, cell division is vigorous, accompanied by multiple substances metabolism. Among the top 10 enriched KEGG pathways in comparison group A vs B, there are four KEGG pathways related to the synthesis of secondary metabolites, including flavonoid biosynthesis (ko00941), phenylpropanoid biosynthesis (ko00940), stilbenoid, diarylheptanoid and gingerol biosynthesis (ko00945), and flavone and flavonol biosynthesis (ko00944) (Table 4). These secondary metabolites may have a significant influence on the early stage of PLB development. In addition, two KEGG pathways are related to amino acid metabolism (ko00350, ko00360) and two are related to energy metabolism (ko00710, ko00910) (Table 4). Among the top 10 pathways of KEGG enrichment in comparison group $B$ vs $C$, several pathways related to metabolism were uniquely enriched, including isoquinoline alkaloid

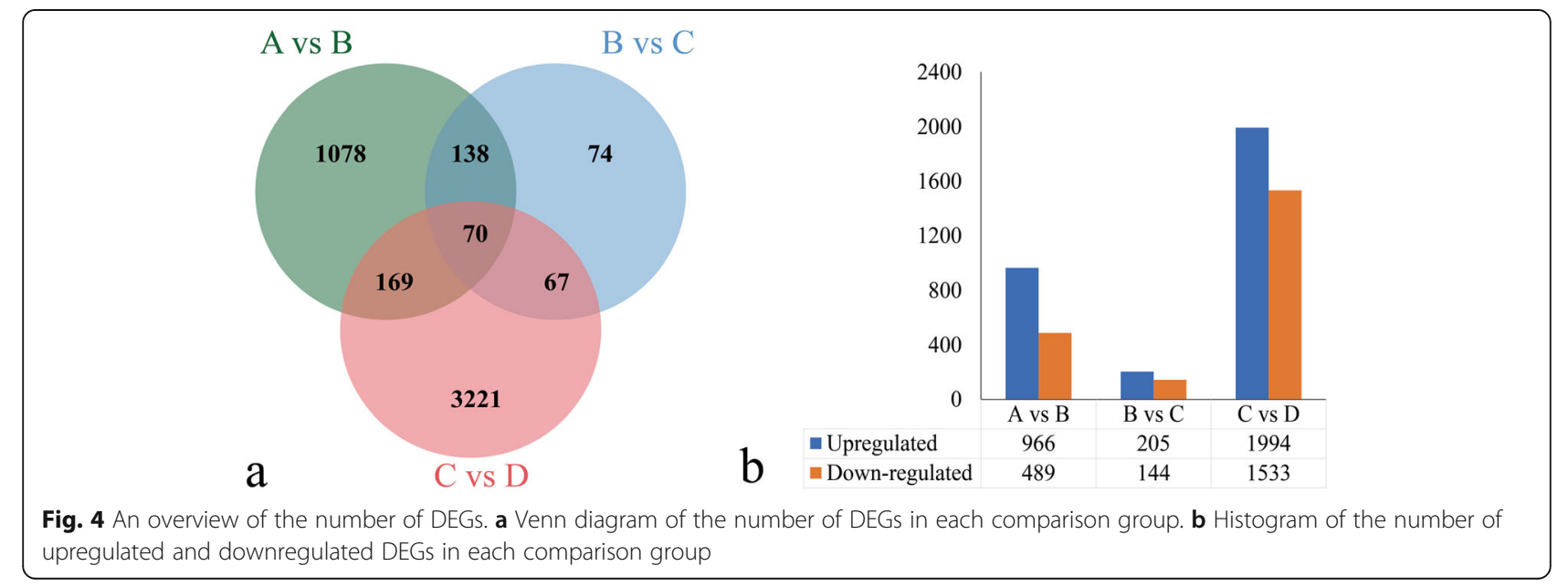


Table 3 Statistics of DEGs annotation in each comparison groups

\begin{tabular}{lllllllll}
\hline DEG Set & Swiss-Prot & GO & KEGG & COG & KOG & Pfam & NR & Total \\
\hline A vs B & 682 & 260 & 882 & 1180 & 293 & 488 & 890 & 1180 \\
B vs C & 194 & 58 & 230 & 309 & 57 & 92 & 252 & 309 \\
C vs D & 1538 & 617 & 2067 & 2804 & 592 & 1225 & 2068 & 2804 \\
\hline
\end{tabular}

biosynthesis (ko00950), tropane, piperidine and pyridine alkaloid biosynthesis (ko00960), arginine and proline metabolism (ko00330), and glycerolipid metabolism (ko00561) (Table 4). Moreover, two KEGG pathways are related to amino acid metabolism (ko00350, ko00360) (Table 4). Buds are formed at stage D. In C vs D, DEGs are significantly enriched in photosynthesis (ko00195), photosynthesis - antenna proteins (ko00196) pathway (Table 4).

DEGs related to IAA metabolism and signaling

IAA plays an important role in the development of PLBs. A total of 31 DEGs involved in IAA synthesis,

Table 4 List of the top 10 significant enrichment pathways for DEGs

\begin{tabular}{|c|c|c|c|c|}
\hline Pathway ID & ko & enrichment factor & q value & gene number \\
\hline \multicolumn{5}{|l|}{ A VS B } \\
\hline Flavonoid biosynthesis & ko00941 & 9.49 & $7.55 \mathrm{E}-11$ & 19 \\
\hline Glycolysis / Gluconeogenesis & ko00010 & 4.25 & $6.93 \mathrm{E}-10$ & 30 \\
\hline Phenylpropanoid biosynthesis & ko00940 & 4.63 & 7.51E-09 & 24 \\
\hline Tyrosine metabolism & ko00350 & 5.75 & $2.23 \mathrm{E}-06$ & 14 \\
\hline Phenylalanine metabolism & ko00360 & 4.85 & 2.60E-06 & 16 \\
\hline Stilbenoid, diarylheptanoid and gingerol biosynthesis & ko00945 & 9.32 & $9.45 \mathrm{E}-05$ & 7 \\
\hline Flavone and flavonol biosynthesis & ko00944 & 6.28 & 0.0003917 & 8 \\
\hline Circadian rhythm - plant & ko04712 & 4.95 & 0.0007079 & 9 \\
\hline Carbon fixation in photosynthetic organisms & ko00710 & 2.78 & 0.0017219 & 16 \\
\hline Nitrogen metabolism & ko00910 & 3.86 & 0.0079 & 8 \\
\hline \multicolumn{5}{|l|}{ B VS C } \\
\hline Phenylalanine metabolism & ko00360 & 10.66 & 0.0002006 & 7 \\
\hline Phenylpropanoid biosynthesis & ko00940 & 5.81 & 0.0151141 & 6 \\
\hline Pentose and glucuronate interconversions & ko00040 & 8.49 & 0.0173551 & 4 \\
\hline Isoquinoline alkaloid biosynthesis & ko00950 & 12.26 & 0.0209329 & 3 \\
\hline Tropane, piperidine and pyridine alkaloid biosynthesis & ko00960 & 10.51 & 0.0271453 & 3 \\
\hline Circadian rhythm - plant & ko04712 & 8.28 & 0.0456279 & 3 \\
\hline Tyrosine metabolism & ko00350 & 6.19 & 0.0886087 & 3 \\
\hline Arginine and proline metabolism & ko00330 & 4.13 & 0.0993424 & 4 \\
\hline Glycerolipid metabolism & ko00561 & 4.94 & 1 & 3 \\
\hline Flavone and flavonol biosynthesis & ko00944 & 7.88 & 1 & 2 \\
\hline \multicolumn{5}{|l|}{ C VS D } \\
\hline Photosynthesis - antenna proteins & ko00196 & 12.03 & $1.14 \mathrm{E}-16$ & 21 \\
\hline Photosynthesis & ko00195 & 7.91 & $3.79 \mathrm{E}-11$ & 39 \\
\hline Carotenoid biosynthesis & ko00906 & 3.94 & 0.0032052 & 11 \\
\hline Fatty acid elongation & ko00062 & 4.72 & 0.0150914 & 7 \\
\hline Linoleic acid metabolism & ko00591 & 6.03 & 0.0235607 & 5 \\
\hline Pentose and glucuronate interconversions & ko00040 & 2.64 & 0.0336898 & 12 \\
\hline Glyoxylate and dicarboxylate metabolism & ko00630 & 2.08 & 0.0304964 & 19 \\
\hline Cyanoamino acid metabolism & ko00460 & 2.57 & 0.0322172 & 12 \\
\hline Cutin, suberine and wax biosynthesis & ko00073 & 6.11 & 0.0402492 & 4 \\
\hline Alanine, aspartate and glutamate metabolism & ko00250 & 2.12 & 0.0397802 & 16 \\
\hline
\end{tabular}



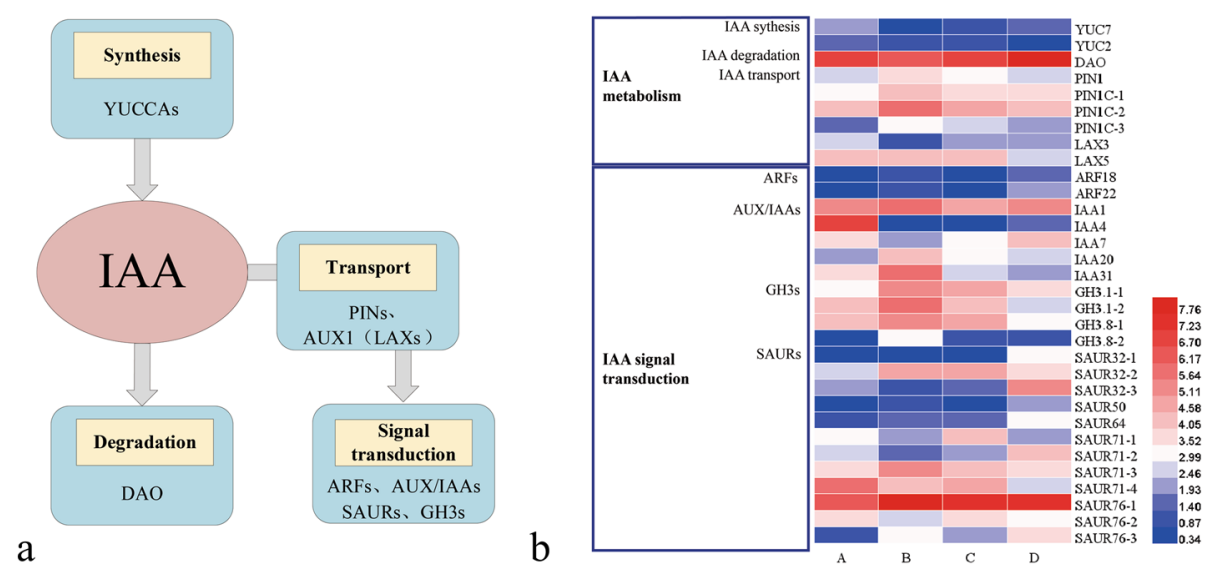

Fig. 5 The main pathway and heatmap of DEGs related to IAA. a IAA synthesis, transport, degradation, and signal transduction pathways. $\mathbf{b}$ Heatmap of DEGs related to IAA synthesis, transport, degradation, and signal transduction. The scale bar is shown as the log2 (FPKM+1) value. The horizontal coordinates A to D indicate the growth stages A to D

degradation, transport, and signal transduction were analyzed (Fig. 5a). In this study, 38 key genes associated with IAA metabolism were identified, including 8 DEGs (Fig. 5b; Supplemental Table S2). Of the 10 YUCs that were annotated, only YUC7 (TRINITY_DN38241_c1_g1) was downregulated at stage $\mathrm{B}$. One $D A O$ (TRINITY DN54506_c1_g1) was upregulated at stage D. The remaining genes related to IAA biosynthesis and deactivation showed no differential expression between the comparisons of adjacent growth stages. Compared with stage A, the expression of YUC2 (TRINITY_DN56795_ c0_g1) and TAR2 (TRINITY_DN31565_c4_g7) was significantly downregulated at stage D. During the formation and development of PLBs, the expression patterns of these two genes were similar, and both decreased continuously.

A total of 13 PIN genes were annotated with different expression patterns (Supplemental Table S2). Four PIN genes (TRINITY_DN53433_c1_g1; TRINITY_DN62381_ c1_g2; TRINITY_DN66850_c1_g1; TRINITY_DN67065_ c2_g2) were significantly upregulated at stage B compared with stage A (Fig. 5b). It can be inferred that these PINs mediated IAA polar transportation during PLB formation. There was no significant difference in the expression level of other PINs between successive growth stages.

An AUX1 and nine LAXs were annotated in the transcriptome data. As the PLB developed, the expression level of $A U X 1$ and most of LAXs was stable. Two LAXs showed different expression patterns. The expression level of LAX5 (TRINITY_DN69997_c0_g1) decreased at stage D. The expression level of LAX1 (TRINITY DN63572_c1_g2) decreased at stage B (Fig. 5b). Therefore, it can be speculated that the different $L A X$ genes may have independent functions at different PLB developmental stages.
According to the plant hormone signal transduction pathway (ko04075) of KEGG, there were mainly five gene families involved in auxin signal transduction, including TRANSPORT INHIBITOR RESPONSE 1 (TIR1), AUXIN/INDOLE-3ACETIC ACID (AuX/IAA), AUXIN RESPONSE FACTORS (ARFs), Gretchen Hagen3s (GH3s), and Small Auxin-Up RNAs (SAURs). These auxin responsive genes allow the plants to sense and respond to auxin signals and precisely regulate plant growth and development. During the development of PLBs, 139 genes belonging to these gene families were found to be expressed. Among these genes, there were 23 DEGs in the comparison of $A$ vs $B, B$ vs $C$, and $C$ vs D (Fig. 5b; Supplemental Table S2). The expression patterns of the three auxin early response factors in the auxin signal transduction pathway are complex because they are all large gene families with functionally redundant members. Compared with the stage A, IAA2O (TRINITY_DN63682_c1_g2), IAA31 (TRINITY_ DN39077_c0_g1), four SAUR genes (TRINITY_ DN54779_c0_g1; TRINITY_DN36365_c0_g1; TRINITY_ DN42107_c0_g1; TRINITY_DN42107_c1_g1), and four GH3 genes (TRINITY_DN60352_c0_g1; TRINITY_ DN67678_c0_g1; TRINITY_DN67678_c0_g2; TRINITY_ DN69497_c0_g1) were significantly upregulated at stage B. On the contrary, IAA1 (TRINITY_DN63237_c1_g1) and IAA7 (TRINITY_DN64569_c0_g1) were downregulated. During PLB formation, more auxin early response genes were upregulated than downregulated. In comparison group B vs C, IAA1 (TRINITY_DN63237_c1_ g1), IAA31 (TRINITY_DN39077_c0_g1), SAUR50 (TRINITY_DN47796_c0_g1), and SAUR71 (TRINITY_ DN29410_c0_g1) were significantly upregulated while IAA20 (TRINITY_DN63682_c1_g2) was significantly downregulated. In comparison group $\mathrm{C}$ vs $\mathrm{D}, I A A 4$ (TRINITY_DN36308_c0_g1) and five SAUR genes 
(TRINITY_DN62934_c0_g2; TRINITY_DN27590_c0_g1; TRINITY_DN32177_c0_g1; TRINITY_DN36045_c4_g2; TRINITY_DN29019_c0_g1) were significantly upregulated while GH3.1 (TRINITY_DN67678_c0_g1), GH3.8 (TRINITY_DN67678_c0_g2) and two SAUR71 (TRINITY_DN50430_c0_g2; TRINITY_DN29410_c0_g1) were significantly downregulated. For the analysis of auxin early response factors, the number of genes with a significant difference was the least in comparison group $\mathrm{B}$ vs $\mathrm{C}$ and the most in comparison group $\mathrm{A}$ vs $\mathrm{B}$.

\section{DEGs related to another hormone metabolism and signaling}

We identified four DEGs related to GA metabolism and seven DEGs related to JA metabolism and signaling (Fig. 6; Supplemental Table S3). Gibberellin 20-oxidases (GA20oxs) were major biosynthetic enzymes of some GAs $[46,47]$. In our study, two GA20ox1B (TRINITY_ DN52187_c0_g1; TRINITY_DN42443_c0_g1) genes were downregulated at stage D. Gibberellin 2-oxidases (GA2oxs) can deactivate bioactive GAs [48]. A $G A 2_{O X} 1$ (TRINITY_DN50547_c1_g1) was significantly upregulated at stage B and a GA2 OX 2 (TRINITY_DN41700_c3_ g2) was significantly downregulated at stage D (Fig. 6).

Figure 6 showed that a total of five DEGs related to JA synthesis, including two Lipoxygenase 2 (LOX2), Allene oxide cyclase (AOC), Allene oxide synthase 1 (AOS1) and Allene oxide synthase 2 (CYP74A2) were significantly upregulated at stage D (Supplemental Table S3). Two DEGs involved in the JA signal transduction pathway. TIFY $6 b$ (TIFY6B) was significantly upregulated at stage $\mathrm{B}$ and TIFY 10a (TIFY10A) was upregulated at stage D.

In addition, ten DEGs involved in brassinosteroid, ethylene, cytokinine, and abscisic acid signal transduction pathway (Fig. 6; Supplemental Table S3). In the comparison group A VS B, Abscisic acid receptor PYL2 (TRINITY_DN50759_c2_g2) of ABA signal transduction pathway was significantly upregulated and BRI1 kinase inhibitor 1 (BKI1) (TRINITY_DN57604_c0_g1) of brassinostteroid signal transduction pathway was significantly downregulated. In the comparison group B vs C, there were no DEGs related to these plant hormones metabolism and signaling. In the comparison group $\mathrm{C}$ vs $\mathrm{D}$, the expression levels of five genes involved in plant hormone signal transduction pathway were upregulated, including ETHYLENE INSENSITIVE 3 (EIN3) (TRINITY_DN69902_c2_g2) and Ethylene-responsive transcription factor $1 B$ (ERF1B) (TRINITY_DN33907_c0_g1) of ethylene signal transduction pathway, Two-component response regulator ARR9 (ARR9) (TRINITY_DN66618_ c1_g1) of zeatin signal transduction pathway, BRI1 kinase inhibitor 1 (BKI1) (TRINITY_DN57604_c0_g1) of brassinostteroid signal transduction pathway, and ankyrin repeat-containing protein NPR5 (NPR5) (TRINITY_
DN67985_c1_g1) of salicylic acid signal transduction pathway. On the contrary, Brassinosteroid LRR receptor kinase BRI1 (BRI1) (TRINITY_DN69717_c2_g1) of brassinostteroid signal transduction pathway, protein phosphatase 2C 3 (AIP1) (TRINITY_DN68734_c0_g1) of abscisic acid signal transduction pathway, and ethylene response sensor 1 (ERS1) (TRINITY_DN42513_c0_g1) of ethylene signal transduction pathway were significantly downregulated at stage $\mathrm{D}$.

\section{DEGs related to somatic embryogenesis}

In this study, a total of 15 genes related to somatic embryogenesis mentioned above were annotated (Supplemental Table S4). Among these genes, SERK2, BBM2, two CLV2, WUS, and six WOXs expressed at all growth stages with low expression levels and without specific high expression during PLBs formation and development. In our transcriptome, except for SERK2, no other members of SERK family were detected. The expression levels of some genes related to somatic embryogenesis were significantly different at different growth stages. Compared with stage A, WOX8 (TRINITY_DN38477_c0_g1) and BBM1 (TRINITY_ DN51934_c0_g1) were upregulated at the stage B (Fig. 7). Subsequently, the expression of $B B M 1$ decreased at stage $\mathrm{D}$, while WOX8 did not. WOX11 (TRINITY_DN36450_c0_g2) and BBM2 (TRINITY_DN67396_c0_g1) were downregulated at the stage of shoot formation (Fig. 7). These DEGs may regulate the development and differentiation of PLB.

\section{DEGs related to photosynthesis}

Photosynthesis is a crucial biological process for plant survival. Plants can convert solar energy into organic

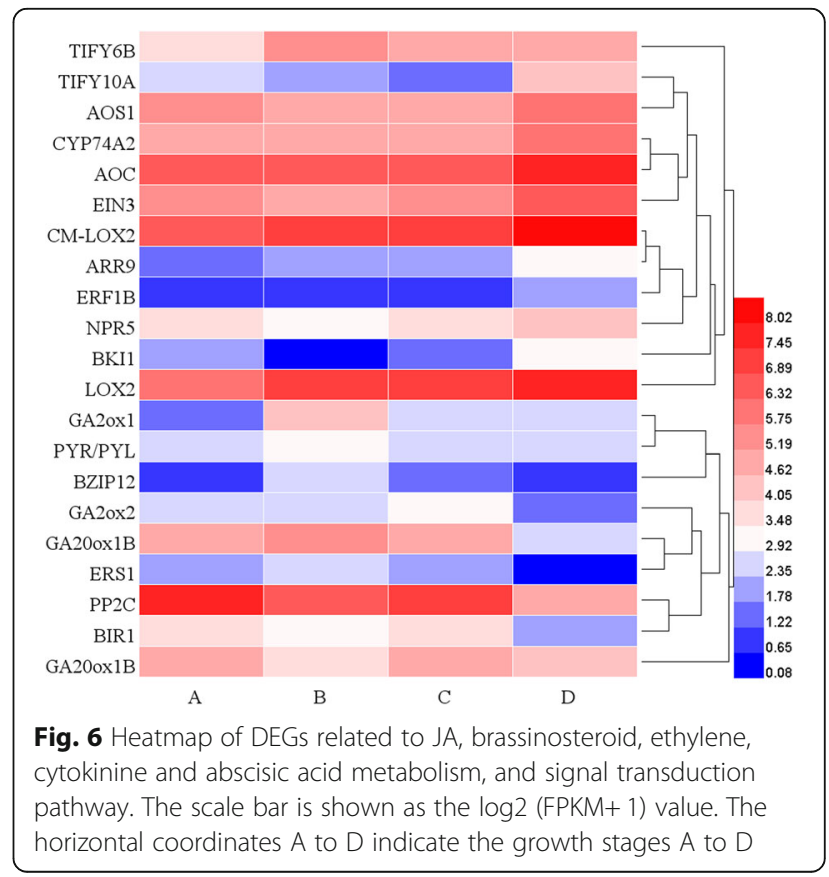




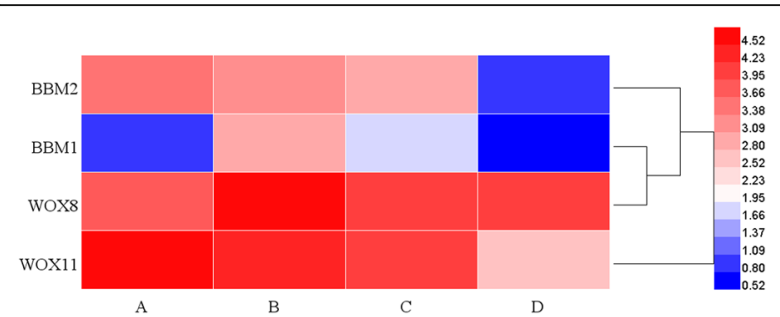

Fig. 7 Heatmap of DEGs related to somatic embryogenesis. The scale bar is shown as the log2 (FPKM+1) value. The horizontal coordinates $A$ to $D$ indicate the growth stages $A$ to $D$

matter and oxygen through complex light and carbon reactions. Photosystem B (PSII), photosystem I (PSI), light-harvesting complex (LHC), Cytochrome $b_{6} f$ (Cyt $\mathrm{b}_{6} \mathrm{f}$ ), and adenosine triphosphate (ATP) synthase are key photosynthetic complexes with unique functions [18]. The genes related to the above complex are summarized in two KEGG pathways, photosynthesis (ko00196) and photosynthesis-antenna proteins (ko00195). A total of 36 and 21 differentially expressed genes were detected in photosynthesis-antenna proteins and photosynthesis pathways, respectively (Supplemental Table S5). In comparison group $\mathrm{C}$ vs $\mathrm{D}$, most genes related to photosynthesis were upregulated and only two genes were downregulated, all of which were enriched in photosynthesis and photosynthesis-antenna proteins pathway. No genes belonging to photosynthesis and photosynthesisantenna proteins pathway shown significant differential expression between group $\mathrm{B}$ and group $\mathrm{C}$. In comparison group A vs $\mathrm{B}$, two psaD (TRINITY_DN66236_c1 g1; TRINITY_DN72036_c3_g2) were downregulated and no genes related to photosynthesis were upregulated.

\section{Reliability validation of DEG expression via qRT-PCR}

A total of 12 genes annotated in the transcriptome were selected for quantitative real-time polymerase chain reaction (qRT-PCR) to validate the reliability of the transcriptome sequencing data, most of which were related to plant hormone signal or meristem development. The selected genes had different expressions. For example, both methods validated the high expression of $A D H 1$ and $I A A$ at growth stage $\mathrm{B}$ and $L O X 2$ at growth stage $\mathrm{D}$. The stable expression levels of RPS3A and RPK1 were also verified by both methods (Fig. 8). The trend of the expression pattern obtained by qRT-PCR and RNA-seq of each gene was mostly the same except for a few genes in individual stages.

\section{Discussions}

\section{Initiation and development of PLBs}

In orchids, PLBs can be induced directly from explants or indirectly from callus $[49,50]$. So far, it has not been reported that PLBs of Paphiopedilum can occur directly from explants. In this study, PLBs were induced from protocorm origin meristem, which is similar to callus, with the ability of continuous proliferation and differentiation. It suggests that the fate of cells may be determined at this stage. Orchids have a unique embryo developmental and germination process. Embryo development arrest at a stage comparable to the globular stage of Arabidopsis embryogenesis [10, 51]. As a result, matured embryos are poorly developed without polarized embryo axis establishment. They failed to finish cell fate determination and formation of a body plan. This part is compensated by the presence of protocorm during the late stage of germination. Plentiful DEGs of the comparison group A vs B were enriched in secondary metabolite metabolism, amino acid metabolism, and energy metabolism. Hence, the formation of PLB was accompanied by active energy metabolism as well as multiple substances transport and metabolism (Table 4).

The primary roles of protocorm/PLBs are to establish apical and basal polarity, cell differentiation, tissue specification, and eventually leading to the shoot generation. With the formation of shoots, many genes related to photosynthesis and photosynthesis-antenna proteins were significantly up-regulated. Photosynthesis is essential for the survival and development of plantlets. PLB gradually develops the photosynthetic apparatus and capacity for further autotrophy in the regeneration process. Photosynthetic antenna proteins, which are specialized pigmentprotein complexes, allowing for the capture of energy from sunlight, participating in the initial step of photosynthesis [52]. It suggests that PLBs begin to turn green and form leaves at stage $D$, which enables explants to obtain energy and nutrition through photosynthesis.

Protocorm gives rise to plantlet through the formation of SAM. PLBs have a similar developmental process. The histological observation showed that PLBs of Paphiopedilum had a distinct gradient of cell size, with the smaller meristem cells occupying the future shoot pole on the surface and the larger cells located inside (Fig. 2). Similar histological results were also observed in Phalaenopsis amabilis. PLBs were composed of smaller compact meristematic cells on the surface of explants at an early stage [50]. Moreover, in Epidendrum ibaguense, similar small compact cells composed the SAM of protocorm [10]. The ability of PLB cells to divide rapidly makes them ideal explants for micropropagation and transformation studies. Despite the great advantage of PLB in large scale production and fundamental research, the regulating mechanism of PLB initiation and maintenance in Paphiopedilum remains unclear.

\section{The change of endogenous hormones levels on PLB development}

The level of the major plant endogenous hormones IAA, GA, ABA, JA, and TZR were investigated during the 


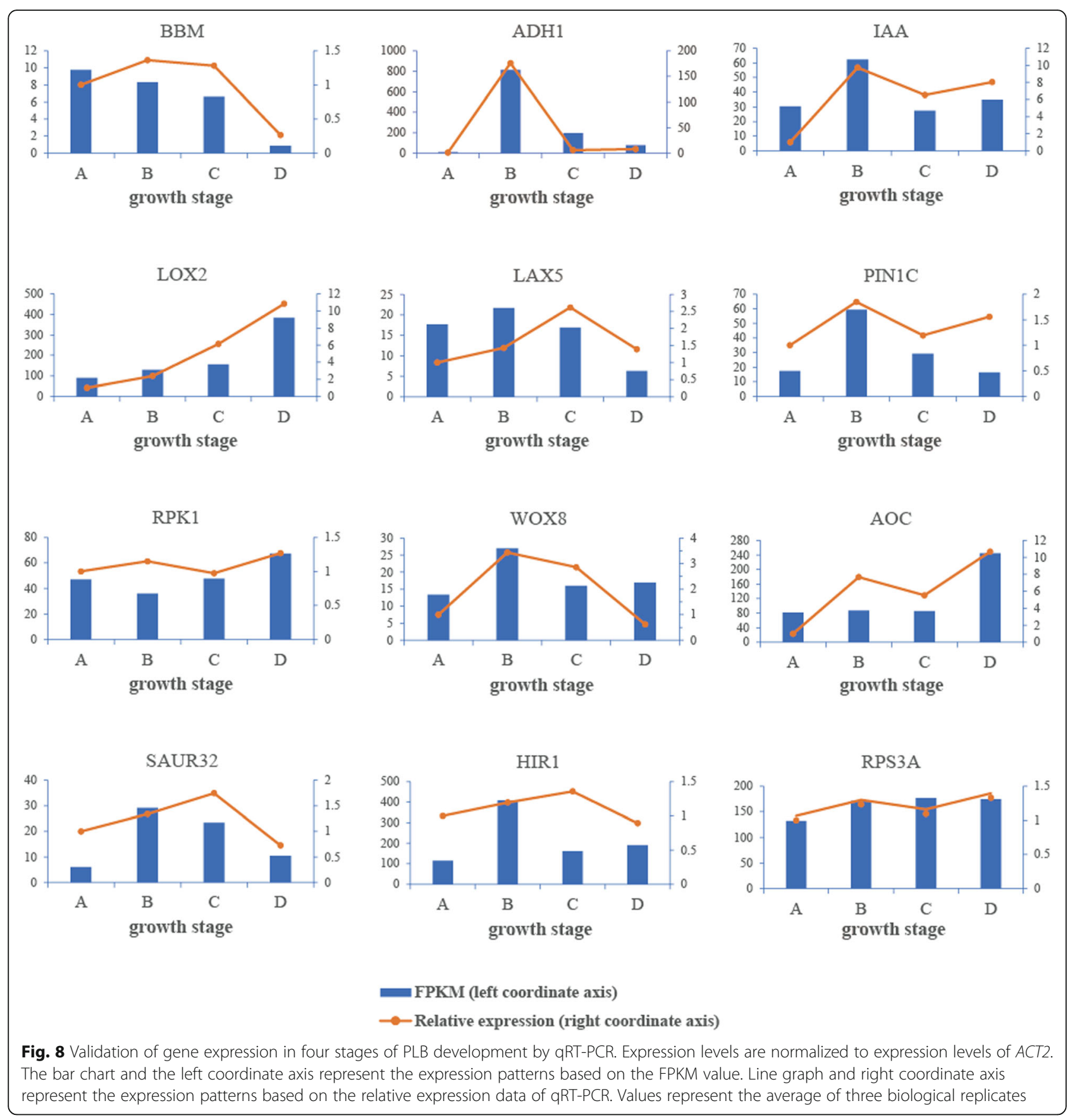

four developmental stages of PLB. The results showed that the IAA level increased significantly during the latter two stages of PLB development. The accumulation of IAA might contribute to shoots emergence from PLBs. In Cattleya tigrine, a similarly significant rise of endogenous IAA content occurred when PLBs differentiated into shoots [53]. Besides the absolute contents, the transportation and distribution of auxin are crucial for PLB formation and shoot development [25]. Uniform auxin distribution helps maintain a dedifferentiated state until auxin is transported to specific locations to stimulate differentiation [54]. Polar auxin transport, mediated by PIN and AUX/LAX proteins, regulates the auxin distribution. The increased expression of four PaphPINs at stage B suggested that PINs-mediated auxin transport affects the development of $P$. SCBG Huihuang90 PLBs. Polar auxin transport analogously affected protocorm development in other orchids, such as Spathoglottis plicata. Lindleyana [26]. The function of LAXs during PLBs had not been studied. According to the expression 
pattern of two differentially expressed $L A X$ in this study, it can be speculated that PaphLAX1 was primarily involved in PLBs development, while PaphLAX5 was primarily involved in shoots formation. Auxin early response genes, such as $A U X / I A A, G H 3$, TIR1, and $A R F$, were reported to regulate shoot initiation and leaf development $[55,56]$. Although the specific regulatory role has not been determined, these genes were potential candidates for PLBs developmental regulators. Further functional studies on the metabolism and signal transduction of IAA can be performed to identify their specific roles in PLB development.

The content of GA decreased significantly at the early stage of PLB development, which was consistent with the up-regulation of PaphGA2 OX1. Previous studies showed that GA2ox can deactivate bioactive GAs and were expressed at the base of the SAM, restricting the influx of bioactive GA to regulate meristem function in several species [40, 44, 47]. GA is incompatible with meristem activities, and a low GA level is necessary for SAM activity [44]. JA content increased significantly with the differentiation of shoot from PLB. This was consistent with the conclusion that exogenous application of JA stimulated the PLB and shoot formation in hybrid Cymbidium [45]. The upregulation of the JA synthesis genes $L O X 2, A O C, A O S 1$, and CYP74A2 may contribute to the increase in JA level.

PLB initiation of Paphiopedilum may be a unique process, distinct from somatic embryogenesis

In recent years, the biological nature of PLBs has been controversial. PLBs are ideal explants for micropropagation because they have regeneration potential. Organogenesis and somatic embryogenesis are both morphogenetic processes leading to plantlet regeneration. PLBs are generally considered "somatic embryos" of the orchids because of their similarities in morphology and cell wall composition $[8,9,57,58]$. To investigate whether PLB development of Paphiopedilum follows the somatic embryogenesis program, the expression patterns of the classic embryo markers including SERK, BBM, CLV , and WUS were examined. These embryonic markers are generally enriched in zygotic and somatic embryos, and their functions have been demonstrated to regulate the development of embryonic fate [17-19]. As shown in Supplemental Table S4, the expression level of PaphSERK, PaphBBM1, PaphCLV, and PaphWUS were either minimally detectable or remained consistent during the whole PLB developmental process. This shows that these genes were not suitable as marker genes for PLBs and that the molecular mechanisms of Paphiopedilum PLBs formation and somatic embryogenesis are different. However, PaphBBM2 is an exception, whose function is important for cell proliferation and morphogenesis [59]. This conclusion is consistent with a recent study in Phalaenopsis aphrodite. Comparative transcriptome analysis of Phalaenopsis aphrodite showed that protocorm/PLB and somatic embryo shared few similarities in terms of gene expression profiles [16]. In addition, somatic tissues of Phalaenopsis aphrodite are considered morphologically different from PLBs [60]. Based on these results, it was proposed that PLB development of Phalaenopsis aphrodite is unique to shoot organogenesis instead of embryogenesis.

On the other hand, the initiation of cell division and establishment of auxin maxima are commonly observed at the early stage of de novo organogenesis $[61,62]$. The endogenous IAA level increased, and the IAA biosynthesis, transportation, and signaling transduction genes were differentially expressed. In addition, the endogenous GA level decreased, which is consistent with previous reports that GA inactivation is required for the SAM initiation [63]. Taken together, PLB initiation of Paphiopedilum may be a unique process combining the characteristics of both organogenesis and somatic embryogenesis.

\section{Expression of PaphWOX8 may be associated with PLB initiation}

Since PLB development in Paphiopedilum may not follow the embryogenesis program similar to the model plants, searching for the genes that contribute to PLB initiation and development is important. Among the differentially expressed transcription factors (TF), the class TF PaphWOX8 and PaphWOX11 were particularly interesting because their expression level was correlated with the initiation of PLB and declined as the shoot formation started (Supplemental Table S4). Several members of the WOX family have been found to redundantly promote cell proliferation and prevent premature differentiation in meristematic tissues [64, 65]. In Arabidopsis, AtWOX2, AtWOX8, and AtWOX9 can regulate asymmetric embryo lineage development [66]. Some of the WOX family genes can be activated by auxin during de novo organogenesis in herbaceous organisms [67, 68]. Functional characterization of these genes may help in identifying gene regulatory networks unique to Paphiopedilum PLBs.

\section{Conclusion}

The transcriptome and endogenous hormone profile of $P$. SCBG Huihuang90 PLBs are reported here for the first time. The results revealed that a complex molecular regulatory network coordinates the induction and development of PLBs. Potential candidate genes involved in PLBs development are summarized. A variety of endogenous hormones co-regulate the development of PLBs. The histological characteristics of PLBs indicate 
that the cells of PLBs demonstrate a structure polarity. This study further supports the understanding and mechanism of PLBs initiation and development.

\section{Methods}

\section{Plant materials}

The Paphiopedilum species used in this study were hybridized by our lab and named P. SCBG Huihuang90. The seed parent was $P$. SCBG Prince, which was registered in The International Orchid Register (http://apps. rhs.org.uk/horticulturaldatabase/orchidregister/ orchiddetails.asp?ID=972703) on 21 Feb, 2014. The pollen parent is $P$. SCBG Miracle, which was registered in The International Orchid Register (http://apps.rhs. org.uk/horticulturaldatabase/orchidregister/ orchiddetails.asp?ID=963533) on 8 Mar, 2013. Both the seed parent and pollen parent were planted in a greenhouse in the South China Botanical Garden, Guangzhou, China and were cultivated under natural light with an average temperature and relative humidity ranging from $8 \sim 32{ }^{\circ} \mathrm{C}$ and $70 \sim 98 \%$, respectively. After flowering and being artificially pollinated, mature seed capsules were collected for follow-up experiments.

\section{Seed germination and PLB induction}

Capsules of $P$. SCBG Huihuang90 were washed with $70 \%$ alcohol three times and treated with $0.10 \%$ mercuric chloride for $20 \mathrm{~min}$. After washing with sterile water three times, capsules were cut, and seeds were sowed in a seed germination medium made of Hyponex No. 26 medium [69] supplemented with $0.5 \mathrm{~g} / \mathrm{L}$ activated carbon and $1.0 \mathrm{mg} / \mathrm{L}$ NAA. After 3 months, protocorms formed and were transferred to half-strength MS medium (Murashige and Skoog 1962) [70], which contained half-strength macro- and micro-elements of MS salts supplemented with $0.05 \mathrm{mg} / \mathrm{L} \mathrm{2,4-dichlorophenox-}$ yacetic acid (2,4-D) to induce the meristem mass. Meristem mass formed after 2 months and were transferred to the half-strength MS medium supplemented with $0.05 \mathrm{mg} / \mathrm{L}$ 2,4-D to induce PLBs. Subculture was conducted every 4 weeks. PLBs formed after 2 months and developed into different growth stages. PLBs were subcultured into the same medium every 2 months. Differentiated PLBs were transferred to PRG-free half-strength MS medium and cluster shoots formed after approximately 2 months.

The $\mathrm{pH}$ of all mediums was adjusted to 5.8 before autoclaving at $121^{\circ} \mathrm{C}$ and $104 \mathrm{kPa}$ for $15 \mathrm{~min}$. All plant materials were cultured at $25 \pm 1{ }^{\circ} \mathrm{C}$ and $12 / 12 \mathrm{~h}$ (light/ dark) photoperiod of $40-45 \mu \mathrm{mol} \mathrm{m}^{-2} \mathrm{~s}^{-1}$ under cool white fluorescent tubes. Protocorm explants were cultured in a $9 \mathrm{~cm}$ glass flask with $100 \mathrm{~mL}$ solid medium for follow-up experiments.

\section{Sample collection}

For phytohormone quantification, transcriptome sequencing, and quantitative real-time PCR, plant materials from different growth stages were collected, frozen in liquid nitrogen, and stored in a refrigerator at $-80^{\circ} \mathrm{C}$. Samples from each growth stage were taken at the same time and consisted of three biological replicates. The meristem mass, which had not formed obvious globular protuberance, formed after 2,4-D induction for 2 months. The materials of stage A were the green inner part of the mass of meristem. The materials of stage $B$ were the mass of PLBs. The materials of stage $C$ were the partly differentiated PLBs mass, which contained a mixture of shoots and PLBs. The materials of stage A-C were cultured on half-strength MS medium supplemented with $0.05 \mathrm{mg} / \mathrm{L} 2,4-\mathrm{D}$. The materials of stage D were the cluster shoots cultured on PRG-free halfstrength MS medium. The weights of the samples were based on their experimental requirements.

\section{PLB morphological characterization}

Light microscopy The plant materials from the four growth stages (described above) were observed and photographed under a stereo microscope (Nikon, SMZ745T, Japan) to study the morphological characters.

Paraffin section The samples from the four growth stages (described above) were fixed in formalin acetic acid-alcohol solution (FAA; 70\% ethyl alcohol: glacial acetic acid: $37 \%$ formaldehyde; 18:1:1) for a week. Fixed samples were dehydrated in a series of alcohols $(70,85$, 95,100 , and $100 \%$; v/v) for $1 \mathrm{~h}$. Then, the samples were immersed in an ethanol-xylene mixture (2:1, 1:1, and 1: 2; v/v) for $1 \mathrm{~h}$, and xylene solution for $2 \mathrm{~h}$. Paraffin was added to the solution until saturated at $36^{\circ} \mathrm{C}$ overnight. Next, the temperature was gradually raised to $58^{\circ} \mathrm{C}$, and xylene was replaced by paraffin. Finally, the materials were embedded by paraplast after soaking in pure paraffin for $3 \mathrm{~h}$. The wax blocks were sliced into $8 \mu \mathrm{m}$ segments with a microtome (KEDEE, China). The dye used was Ehrlich's haematoxylin (Biosharp, China), 1\% safranin O (Solarbio, China), and 0.5\% fast green dyes (Solarbio, China). The sections were observed and photographed under a biological microscope (Nikon, E200, Japan).

Phytohormone quantification The determination of plant hormones was performed by high performance liquid chromatography-tandem mass spectrometry (HPLC-MS/MS). Tissue culture materials from each of the four growth stages were taken as experimental materials. Plant samples $(50 \mathrm{mg})$ were ground into a powder in liquid nitrogen and added to 10 times the volume of 
acetonitrile solution. The material was extracted overnight at $-4{ }^{\circ} \mathrm{C}$. After centrifugation at $12,000 \times$ g for 5 $\mathrm{min}$, the supernatant was collected. To extract the hormone, 5 times the volume of acetonitrile solution was added to the precipitate, and the supernatant was collected and merged with the previous supernatant. After adding $25 \mathrm{mg} \mathrm{CNW}$ C18 QuEChers packing, the mixture was vortexed vigorously for $30 \mathrm{~s}$ and centrifuged at $10,000 \times \mathrm{g}$ for $5 \mathrm{~min}$. The supernatant was collected and dried with nitrogen stream. The residues were redissolved in $200 \mu \mathrm{L}$ methyl alcohol and filtered through $0.22 \mu \mathrm{m}$ organic phase membrane. The mass spectrometer used is the Qtrap6500 (Agilent, America).

The results of the samples in each growth stage were represented by the average value of three biological replicates. The treatment data were subjected to analysis of variance (ANOVA) using IBM SPSS Statistics version 20. Duncan's multiple range test at $P$ value $<0.05$ was performed with stage A as the control.

RNA extraction Column Plant RNAout2.0 (Tiandz Inc., Beijing, China) was used for total RNA extraction performed according to the manufacturer's instructions. Approximately $100 \mathrm{mg}$ of each sample was used to extract RNA. The RNA was assessed using agarose gel electrophoresis, Nanodrop One (Nanodrop Technologies Inc., DE, USA), and Agilent 2100 (Agilent Technologies Inc., CA, USA) to confirm the purity, concentration, and integrity, respectively. The $260 / 280 \mathrm{~nm}$ ratios and 260 / $230 \mathrm{~nm}$ ratios of $1.8-2.2$ and $1.6-2.2$, respectively, from the Nanodrop were regarded as pure. Next, the RNA library was constructed, and sequencing was performed by Genepioneer Technologies Corporation (Nanjing, China). HiSeq4000 platform (Illumina Inc.) was used for high-throughput sequencing with a read length of PE150.

De novo assembly and functional annotation of unigenes Transcriptome sequencing was performed on the samples from the four growth stages (described above), with three biological replicates for each stage. Raw data produced by sequencing were processed by removing adapters as well as filtering low quality reads with over $10 \%$ high unknown base $(\mathrm{N})$ reads to obtain high quality clean data. Phred quality score Q20 and Q30 and GC-content of clean reads were calculated. Clean reads were assembled to finally obtain the unigene library of $P$. SCBG Huihuang90. The quality of transcriptome sequencing libraries was evaluated from three different perspectives: (1) examining the distribution of inserted fragments on unigene to evaluate the randomness of mRNA fragmentation and the degradation of mRNA; (2) drawing the length distribution map of the inserted fragment to evaluate the dispersion degree of the length of the inserted fragment; (3) evaluating whether the library capacity and the mapped reads compared to the unigene library were sufficient by drawing saturation map. All sequence data were uploaded into the BioProject database hosted by the National Center for Biotechnology Information (NCBI) under the BioProject PRJNA684752. Software BLAST (http://blast.ncbi. nlm.nih.gov/Blast.cgi) was used for functional annotations by comparing the information of sequence or amino acid sequence of unigenes to 7 databases: NR, Swiss-Prot, KEGG, COG, KOG, GO, and Pfam.

Unigenes expression and DEGs analysis Bowtie (http://bowtie-bio.sourceforge.net/index.shtml) was used to compare the sequenced reads with unigene library. Fragments per kilobase per million mapped reads (FPKM) value was used to estimate the expression abundance of unigene. DEGs between libraries were identified by DESeq2 (http://www.bioconductor.org/packages/release/ bioc/html/DESeq.html). Fold change represents the ratio of expression quantity between two samples, and the Benjamini-Hochberg approach was used to adjust the $P$ values for controlling the FDR. Unigenes with FDR $<0.05$ and an absolute value log2 (Fold change) $\geq 1$ were considered differentially expressed. KEGG enrichment of DEGs was measured by enrichment factor, $\mathrm{q}$ value, and the number of genes enriched in the corresponding pathway.

Verification of gene expression using qRT-PCR To validate the results of RNA-seq data, quantitative realtime PCR analysis was used to detect the expression levels of the 12 candidate genes. Primers were designed based on the Primer-BLAST [71] and listed in Supplemental Table S6. ACT2 (TRINITY_DN57670_c1_g1) was selected as the reference gene for the normalization of the data. RNA of each growth stage was reverse transcribed using the One-Step gDNA Removal and cDNA Synthesis SuperMix kit (Trans, Beijing, China) according to the instruction manual, and cDNA of approximately $600 \mathrm{ng} / \mu \mathrm{L}$ was obtained. cDNA was diluted three times for subsequent experiments. $1 \mu \mathrm{L}$ cDNA mixed with $0.8 \mu \mathrm{L}$ primer pair $(10 \mu \mathrm{M}), 10 \mu \mathrm{L} 2 \times$ Green $\mathrm{qPCR}$ SuperMix (Trans, Beijing, China), and $8.2 \mu \mathrm{L}$ ddH2O. The mixture was used to carry out qRT-PCR detection on LightCycler 480 System (Roche Diagnostics, Germany). The amplification program was performed as follows: $30 \mathrm{~s}$ at $94^{\circ} \mathrm{C}$ for initial denaturation, 40 cycles of $5 \mathrm{~s}$ at $94^{\circ} \mathrm{C}$ for denaturation, $15 \mathrm{~s}$ at $57^{\circ} \mathrm{C}$ for annealing, $10 \mathrm{~s}$ at $72^{\circ} \mathrm{C}$ for elongation, followed by melting curve program for melting curve analysis. Each sample was processed as three biological replicates and three technical replicates. The relative expression was calculated by the $2^{-\Delta \Delta \mathrm{Ct}}$ method [72]. 


\section{Abbreviations}

PLBs: Protocorm-like bodies; P. SCBG Huihuang90: Paphiopedilum. SCBG Huihuang90; IAA: Indoleacetic acid; JA: Jasmonic acid; GA: Gibberellic acid; SAM: Shoot apical meristem; DEGs: Differentially expressed genes; CITES: International Trade in Endangered Species of Wild Fauna and Flora; ABA: Abscisic acid; HRGPs: Hydroxyproline-rich glycoproteins; TZR: Transzeatin; COG: Clusters of Orthologous Groups; GO: Gene Ontology; KEGG: Kyoto Encyclopedia of Genes and Genomes; KOG: euKaryotic Orthologous Groups; Pfam: Protein family; FDR: False discovery rate; PSII: Photosystem B; PSI: Photosystem; LHC: Light-harvesting complex; Cyt $b_{6}$ f: Cytochrome b $b_{6}$; ATP: Adenosine triphosphate; qRT-PCR: Quantitative real-time polymerase chain reaction; TFs: Transcription factors; FAA: Formalin acetic acid-alcohol solution; HPLC-MS/MS: High performance liquid chromatography-tandem mass spectrometry; NCBI: National Center for Biotechnology Information; FPKM: Fragments per kilobase per million mapped reads; ANOVA: Analysis of variance

\section{Supplementary Information}

The online version contains supplementary material available at https:/doi. org/10.1186/s12864-021-08087-y.

Additional file 1: Supplemental Table S1. Overview of de novo assembly. Supplemental Table S2. Annotated genes related to IAA metabolism and signaling. Supplemental Table S3. DEGs involved in jasmonic acid, brassinosteroid, ethylene, zeatin, salicylic acid and abscisic acid metabolism and signaling transduction. Supplemental Table S4. Annotated genes related to somatic embryogenesis. Supplemental Table S5. DEGs involved in photosynthesis. Supplemental Table S6. Primers used in the reference genes selection.

\section{Acknowledgements}

We acknowledge Mingzhi Li (Genepioneer Biotechnologies) for transcriptome sequencing. We acknowledge Jeemeng Lao, Peihan Chen, and Minghao Liang for the linguistic editing and proofreading during the preparation of this manuscript.

\section{Authors' contributions}

All authors have read and approved the manuscript. BG, LF, and SZ conceived the research project and designed research. BG, $Y Y$ performed the experimental treatment and sampling. $B G, L F$ performed research. $B G, L F, L L$, GM, KW analyzed the data. BG, LF and SZ wrote the manuscript.

\section{Funding}

This work was funded by National Key Research and Development Program of China (2018YFD1000403, 2016YFC0503104), National Natural Science Foundation of China (31902062), Natural Science Foundation of Guangdong Province (2018A030313686), Guangdong Key Technology Research and Development Program (2018B020202001-3), Guangdong Modern Agricultural Industry Technology System Program (2018LM2176, 20209KJ121), Biological Resources Programme, Chinese Academy of Sciences (KFJ-BRP007), Guangzhou Science and Technology Program (201904010305), Guangdong Provincial Key Laboratory of Applied Botany, South China Botanical Garden, and Chinese Academy of Sciences (AB2018002, AB2018026, KF202006).

\section{Availability of data and materials}

All data generated or analyzed during this study are included in this published article and the supplementary information files. The sequence data was deposited in the NCBI database under the BioProject PRJNA684752.

\section{Declarations}

Ethics approval and consent to participate Not Applicable.

\section{Consent for publication}

Not Applicable.

\section{Competing interests}

The authors declare that they have no competing interests.

\section{Author details}

'Key Laboratory of South China Agricultural Plant Molecular Analysis and Gene Improvement, South China Botanical Garden, Chinese Academy of Sciences, Guangzhou 510650, China. ${ }^{2}$ University of Chinese Academy of Sciences, Beijing 100049, China. ${ }^{3}$ Center of Economic Botany, Core Botanical Gardens, Chinese Academy of Sciences, Guangzhou 510650, China.

${ }^{4}$ Guangdong Provincial Key Laboratory of Applied Botany, South China Botanical Garden, Chinese Academy of Sciences, Guangzhou 510650, China.

Received: 14 January 2021 Accepted: 12 October 2021

Published online: 08 November 2021

References

1. World Checklist of Selected Plant Families: Royal Botanic Gardens, Kew. 2020. http://wcsp.science.kew.org/advsearch.do. Accessed 1 July 2021.

2. Appendices | CITES. 2020. https://cites.org/eng/app/appendices.php. Accessed 1 July 2021.

3. Zhang YY, Wu KL, Zhang JX, Deng RF, Duan J, Teixeira da Silva JA, et al. Embryo development in association with asymbiotic seed germination in vitro of Paphiopedilum armeniacum S C Chen et F Y Liu. Sci Rep. 2015; 5(1):16356. https://doi.org/10.1038/srep16356.

4. Diengdoh RV, Kumaria S, Tandon P, Das MC. Asymbiotic germination and seed storage of Paphiopedilum insigne, an endangered lady's slipper orchid. S Afr J Bot. 2017;112:215-24. https://doi.org/10.1016/j.sajb.2017.05.028.

5. Fang L, Xu X, Li J, Zheng F, Li MZ, Yan JW, et al. Transcriptome analysis provides insights into the non-methylated lignin synthesis in Paphiopedilum armeniacum seed. BMC Genomics. 2020;21(1):524. https://doi.org/10.1186/ s12864-020-06931-1.

6. Zeng SJ, Huang WX, Wu KL, Zhang JX. Teixeira da Silva JA, Duan J. in vitro propagation of Paphiopedilum orchids. Crit Rev Biotechnol. 2016;36(3):52134. https://doi.org/10.3109/07388551.2014.993585.

7. Long $B$, Niemiera $A X$, Cheng $Z Y$, Long CL. In vitro propagation of four threatened Paphiopedilum species (Orchidaceae). Plant Cell Tissue Organ Cult. 2010;101(2):151-62. https://doi.org/10.1007/s11240-010-9672-1.

8. Cardoso JC, Zanello CA, Chen JT. An overview of orchid protocorm-like bodies: mass propagation, biotechnology, molecular aspects, and breeding. Int J Mol Sci. 2020;21(3):985. https://doi.org/10.3390/ijms21030985.

9. Lee YI, Hsu ST, Yeung EC. Orchid protocorm-like bodies are somatic embryos. Am J Bot. 2013;100(11):2121-31. https://doi.org/10.3732/ajb.13001 93.

10. Yeung EC. A perspective on orchid seed and protocorm development. Bot Stud. 2017;58(1):33. https://doi.org/10.1186/s40529-017-0188-4.

11. De Conti D, Corredor-Prado JP, Bueno JCF, et al. Differentially expressed proteins in the development of protocorm-like bodies of Cattleya tigrina a. Richard Acta Physiol Plant. 2020:42(12):181. https://doi.org/10.1007/s11738020-03170-5.

12. Zeng SJ, Wang J, Wu KL, Teixeira da Silva JA, Zhang JX, Duan J. in vitro propagation of Paphiopedilum hangianum Perner \& Gruss. Sci Hortic. 2013; 151:147-56. https://doi.org/10.1016/j.scienta.2012.10.032.

13. Ng CY, Saleh NM. In vitro propagation of Paphiopedilum orchid through formation of protocorm-like bodies. Plant Cell Tissue Organ Cult. 2011; 105(2):193-202. https://doi.org/10.1007/s11240-010-9851-0.

14. Soonthornkalump S, Nakkanong K, Meesawat U. In vitro cloning via direct somatic embryogenesis and genetic stability assessment of Paphiopedilum niveum (Rchb.F.) stein: the endangered Venus's slipper orchid. In Vitro Cell Dev Biol-Plant. 2019;55(3):265-76. https://doi.org/10.1007/s11627-019-099817.

15. Le V, Takamura T, Tanaka M. Callus formation and plant regeneration from callus through somatic embryo structures in Cymbidium orchid. Plant Sci. 2004;166(6):1443-9. https://doi.org/10.1016/j.plantsci.2004.01.023.

16. Fang SC, Chen JC, Wei MJ. Protocorms and protocorm-like bodies are molecularly distinct from zygotic embryonic tissues in Phalaenopsis aphrodite. Plant Physiol. 2016;171(4):2682-700. https://doi.org/10.1104/pp.16. 00841.

17. Mendez-Hernandez HA, Ledezma-Rodriguez M, Avilez-Montalvo RN, JuarezGomez YL, Skeete A, Avilez-Montalvo J, et al. Signaling overview of plant somatic embryogenesis. Front Plant Sci. 2019;10. https://doi.org/10.3389/ fpls.2019.00077. 
18. Yang $X Y$, Zhang $X L$. Regulation of somatic embryogenesis in higher plants Crit Rev Plant Sci. 2010;29(1):36-57. https://doi.org/10.1080/0735268090343 6291.

19. Gulzar B, Mujib A, Malik MQ, Sayeed R, Mamgain J, Ejaz B. Genes, proteins and other networks regulating somatic embryogenesis in plants. J Genet Eng Biotechnol. 2020;18(1):31. https://doi.org/10.1186/s43141-020-00047-5.

20. Bayer M, Nawy T, Giglione C, Galli M, Meinnel T, Lukowitz W. Paternal control of embryonic patterning in Arabidopsis thaliana. Science. 2009; 323(5920):1485-8. https://doi.org/10.1126/science.1167784.

21. Haecker A, Gross-Hardt R, Geiges B, Sarkar A, Breuninger H, Herrmann M, et al. Expression dynamics of WOX genes mark cell fate decisions during early embryonic patterning in Arabidopsis thaliana. Dev Camb Engl. 2004; 131(3):657-68. https://doi.org/10.1242/dev.00963.

22. Wang H, Niu HH, Li C, Shen GY, Liu XF, Weng YQ, et al. WUSCHEL-related homeobox1 (WOX1) regulates vein patterning and leaf size in Cucumis sativus. Hortic Res. 2020;7(1):182. https://doi.org/10.1038/s41438-020-00404-y.

23. Lin H, Niu LF, McHale NA, Ohme-Takagi M, Mysore KS, Tadege M. Evolutionarily conserved repressive activity of WOX proteins mediates leaf blade outgrowth and floral organ development in plants. Proc Natl Acad Sci U S A. 2013;110(1):366-71. https://doi.org/10.1073/pnas.1215376110.

24. Jha $P$, Kumar $V$. BABY BOOM (BBM): a candidate transcription factor gene in plant biotechnology. Biotechnol Lett. 2018;40(11-12):1467-75. https://doi. org/10.1007/s10529-018-2613-5

25. Novak SD, Luna LJ, Gamage RN. Role of auxin in orchid development. Plant Signal Behav. 2014;9(10):e972277. https://doi.org/10.4161/psb.32169.

26. Novak SD, Whitehouse GA. Auxin regulates first leaf development and promotes the formation of protocorm trichomes and rhizome-like structures in developing seedlings of Spathoglottis plicata (Orchidaceae). AoB Plants. 2013;5:pls053.

27. Hossain MM, Dey R. Multiple regeneration pathways in Spathoglottis plicata Blume - a study in vitro. S Afr J Bot. 2013;85:56-62. https://doi.org/10.1016/j. sajb.2012.12.005

28. Chen JT, Chang WC. Efficient plant regeneration through somatic embryogenesis from callus cultures of Oncidium (Orchidaceae). Plant Sci. 2000;160(1):87-93. https://doi.org/10.1016/S0168-9452(00)00367-8.

29. Mohanty P, Paul S, Das MC, Kumaria S, Tandon P. A simple and efficient protocol for the mass propagation of Cymbidium mastersii: an ornamental orchid of Northeast India. AoB Plants. 2012;2012:pls023.

30. Shimasaki K, Shiraga T, Fukumoto Y. Effect of methyl jasmonate on organogenesis in shoot cultures of epiphytic and terrestrial Cymbidium species. Environ Control Biol. 2003;41(2):179-82. https://doi.org/10.2525/ ecb1963.41.179.

31. Hong PI, Chen JT, Chang WC. Shoot development and plant regeneration from protocorm-like bodies of Zygopetalum mackayi. In Vitro Cell Dev BiolPlant. 2010;46(3):306-11. https://doi.org/10.1007/s11627-009-9262-2.

32. Teale WD, Paponov IA, Palme K. Auxin in action: signalling, transport and the control of plant growth and development. Nat Rev Mol Cell Biol. 2006 7(11):847-59. https://doi.org/10.1038/nrm2020

33. Won $\mathrm{C}$, Shen $\mathrm{XL}$, Mashiguchi $\mathrm{K}$, Zheng $Z Y$, Dai $X \mathrm{H}$, Cheng $Y F$, et al. Conversion of tryptophan to indole-3-acetic acid by TRYPTOPHAN AMINOTRANSFERASES OF ARABIDOPSIS and YUCCAs in Arabidopsis. Proc Natl Acad Sci U S A. 2011;108(45):18518-23. https://doi.org/10.1073/pnas.11 08436108.

34. Mashiguchi K, Tanaka K, Sakai T, Sugawara S, Kawaide H, Natsume M, et al. The main auxin biosynthesis pathway in Arabidopsis. Proc Natl Acad Sci U S A. 2011;108(45):18512-7. https://doi.org/10.1073/pnas.1108434108.

35. Zhang J, Peer WA. Auxin homeostasis: the DAO of catabolism. J Exp Bot 2017;68(12):3145-54. https://doi.org/10.1093/jxb/erx221.

36. Porco S, Pencik A, Rashed A, Voss U, Casanova-Saez R, Bishopp A, et al. Dioxygenase-encoding AtDAO1 gene controls IAA oxidation and homeostasis in Arabidopsis. Proc Natl Acad Sci U S A. 2016;113(39):1101621. https://doi.org/10.1073/pnas.1604375113.

37. Petrasek J, Mravec J, Bouchard R, Blakeslee JJ, Abas M, Seifertova D, et al. PIN proteins perform a rate-limiting function in cellular auxin efflux. Science. 2006;312(5775):914-8. https://doi.org/10.1126/science.1123542.

38. Zhou JJ, Luo J. The PIN-FORMED auxin efflux carriers in plants. Int J Mol Sci. 2018;19(9):21.

39. Guan L, Li Y, Huang K, Cheng ZM. Auxin regulation and MdPIN expression during adventitious root initiation in apple cuttings. Hortic Res. 2020;7(1): 143. https://doi.org/10.1038/s41438-020-00364-3.
40. Parry G, Marchant A, May S, Swarup R, Swarup K, James N, et al. Quick on the uptake: characterization of a family of plant auxin influx carriers. J Plant Growth Regul. 2001;20(3):217-25. https://doi.org/10.1007/s003440010030.

41. Swarup R, Kargul J, Marchant A, Zadik D, Rahman A, Mills R, et al. Structurefunction analysis of the presumptive Arabidopsis auxin permease AUX1. Plant Cell. 2004;16(11):3069-83. https://doi.org/10.1105/tpc.104.024737.

42. Sakamoto T, Kobayashi M, Itoh H, Tagiri A, Kayano T, Tanaka H, et al. Expression of a gibberellin 2-oxidase gene around the shoot apex is related to phase transition in rice. Plant Physiol. 2001;125(3):1508-16. https://doi. org/10.1104/pp.125.3.1508.

43. Jasinski S, Piazza P, Craft J, Hay A, Woolley L, Rieu I, et al. KNOX action in Arabidopsis is mediated by coordinate regulation of cytokinin and gibberellin activities. Curr Biol. 2005;15(17):1560-5. https://doi.org/10.1016/j. cub.2005.07.023

44. Bolduc N, Hake S. The maize transcription factor KNOTTED1 directly regulates the gibberellin catabolism gene ga20x1. Plant Cell. 2009;21(6): 1647-58. https://doi.org/10.1105/tpc.109.068221.

45. Teixeira da Silva JA. Jasmonic acid, but not salicylic acid, improves PLB formation of hybrid Cymbidium. Plant Tissue Cult Biotechnol. 2013;22(2): 187-92. https://doi.org/10.3329/ptcb.v22i2.14209.

46. Hedden $P$. The current status of research on gibberellin biosynthesis. Plant Cell Physiol. 2020;61(11):1832-49. https://doi.org/10.1093/pcp/pcaa092.

47. Appleford NE, Evans DJ, Lenton JR, Gaskin P, Croker SJ, Devos KM, et al. Function and transcript analysis of gibberellin-biosynthetic enzymes in wheat. Planta. 2006;223(3):568-82. https://doi.org/10.1007/s00425-005-01040.

48. Li C, Zheng LL, Wang XN, Hu ZB, Zheng Y, Chen QH, et al. Comprehensive expression analysis of Arabidopsis GA2-oxidase genes and their functional insights. Plant Sci. 2019;285:1-13. https://doi.org/10.1016/j.plantsci.2019.04. 023.

49. Hardjo PH, Savitri WD. Somatic embryo from basal leaf segments of Vanda tricolor Lindl. Var. pallida. Kne. Life Sci. 2017:3(5):173-9. https://doi.org/10.1 8502/kls.v3i5.990.

50. Chen JT, Chang WC. Direct somatic embryogenesis and plant regeneration from leaf explants of Phalaenopsis amabilis. Biol Plant. 2006;50(2):169-73. https://doi.org/10.1007/s10535-006-0002-8.

51. Lee Yl, Yeung EC, Lee N, Chung MC. Embryo development in the lady's slipper orchid, Paphiopedilum delenatii, with emphasis on the ultrastructure of the suspensor. Ann Bot. 2006;98(6):1311-9. https://doi.org/10.1093/aob/ $\mathrm{mcl} 222$.

52. Lokstein H, Renger G, Goetze JP. Photosynthetic light-harvesting (Antenna) complexes-structures and functions. Molecules. 2021;26(11):3378. https://doi. org/10.3390/molecules26113378.

53. De Conti D, Corredor-Prado JP, Junior DR, et al. Determination of endogenous IAA and carbohydrates during the induction and development of protocorm-like bodies of Cattleya tigrina a. Richard Acta Sci Biol Sci. 2018; 40(1):e37874. https://doi.org/10.4025/actascibiolsci.v40i1.37874.

54. Michniewicz M, Brewer PB, Friml Jl. Polar auxin transport and asymmetric auxin distribution. Arabidopsis Book. 2007:5:e0108.

55. Vernoux T, Besnard F, Traas J. Auxin at the shoot apical meristem. Cold Spring Harb Perspect Biol. 2010;2(4):a001487. https://doi.org/10.1101/ cshperspect.a001487.

56. Leyser O. Regulation of shoot branching by auxin. Trends Plant Sci. 2003: 8(11):541-5. https://doi.org/10.1016/j.tplants.2003.09.008.

57. Balilashaki K, Moradi S, Vahedi M, Khoddamzadeh AA. A molecular perspective on orchid development. J Hortic Sci Biotechnol. 2020;95(5):54252. https://doi.org/10.1080/14620316.2020.1727782

58. Park SY, Huh YS, Paek KY. Common protocols in orchid micropropagation. In: Lee Yl, Yeung ECT, editors. Orchid propagation: from laboratories to greenhouses-methods and protocols. New York: Humana Press; 2018. p. 179-93. https://doi.org/10.1007/978-1-4939-7771-0_8.

59. Boutilier K, Offringa R, Sharma VK, Kieft H, Ouellet T, Zhang LM, et al. Ectopic expression of $B A B Y B O O M$ triggers a conversion from vegetative to embryonic growth. Plant Cell. 2002;14(8):1737-49. https://doi.org/10.1105/ tpc.001941.

60. Chen JC, Tong CG, Lin HY, Fang SC. Phalaenopsis LEAFY COTYLEDON1induced somatic embryonic structures are morphologically distinct from protocorm-like bodies. Front Plant Sci. 2019;10:1594. https://doi.org/10.3389/ fpls.2019.01594

61. Pernisova M, Klima P, Horak J, Valkova M, Malbeck J, Soucek P, et al. Cytokinins modulate auxin-induced organogenesis in plants via regulation 
of the auxin efflux. Proc Natl Acad Sci U S A. 2009;106(9):3609-14. https:// doi.org/10.1073/pnas.0811539106.

62. Yu J, Liu W, Liu J, Qin P, Xu L. Auxin control of root organogenesis from callus in tissue culture. Front Plant Sci. 2017:8:1385. https://doi.org/10.3389/ fpls.2017.01385.

63. Shani $\mathrm{E}$, Yanai $\mathrm{O}$, Ori $\mathrm{N}$. The role of hormones in shoot apical meristem function. Curr Opin Plant Biol. 2006;9(5):484-9. https://doi.org/10.1016/j.pbi.2 006.07.008.

64. Wu XL, Chory J, Weigel D. Combinations of WOX activities regulate tissue proliferation during Arabidopsis embryonic development. Dev Biol. 2007; 309(2):306-16. https://doi.org/10.1016/j.ydbio.2007.07.019.

65. Evd G, Laux T, Rensing SA. The WUS homeobox-containing (WOX) protein family. Genome Biol. 2009;10(12):248.

66. Ueda M, Zhang ZJ, Laux T. Transcriptional activation of Arabidopsis axis patterning genes WOX8/9 links zygote polarity to embryo development. Dev Cell. 2011;20(3):408. https://doi.org/10.1016/j.devcel.2011.03.009.

67. Breuninger $H$, Rikirsch E, Hermann M, Ueda M, Laux T. Differential expression of WOX genes mediates apical-basal axis formation in the Arabidopsis embryo. Dev Cell. 2008;14(6):867-76. https://doi.org/10.1016/j. devcel.2008.03.008.

68. Yu J, Zhang YY, Liu W, Wang H, Wen ST, Zhang YJ, et al. Molecular evolution of auxin-mediated root initiation in plants. Mol Biol Evol. 2020; 37(8):2462. https://doi.org/10.1093/molbev/msz230.

69. Zeng SJ, Chen ZL, KL WU, Zhang JX, Bai CK, Teixeira da Silva JA, et al. Asymbiotic seed germination, induction of calli and protocorm-like bodies, and in vitro seedling development of the rare and endangered Nothodoritis zhejiangensis Chinese orchid. Hortscience. 2011;46(3):460-5. https://doi.org/1 0.21273/HORTSCl.46.3.460.

70. Murashige T, Skoog F. A revised medium for rapid growth and bioassays with tobacco tissue cultures. Physiol Plant. 1962;15(3):473-97. https://doi. org/10.1111/j.1399-3054.1962.tb08052.x.

71. Primer designing tool. 2020. https://www.ncbi.nlm.nih.gov/tools/primer-bla st/index.cgi?LINK_LOC=BlastHome. Accessed 10 May 2020.

72. Livak KJ, Schmittgen TD. Analysis of relative gene expression data using real-time quantitative PCR and the 2(-Delta Delta C(T)) method. Methods. 2001;25(4):402-8. https://doi.org/10.1006/meth.2001.1262.

\section{Publisher's Note}

Springer Nature remains neutral with regard to jurisdictional claims in published maps and institutional affiliations.

Ready to submit your research? Choose BMC and benefit from:

- fast, convenient online submission

- thorough peer review by experienced researchers in your field

- rapid publication on acceptance

- support for research data, including large and complex data types

- gold Open Access which fosters wider collaboration and increased citations

- maximum visibility for your research: over $100 \mathrm{M}$ website views per year

At BMC, research is always in progress.

Learn more biomedcentral.com/submissions 